\title{
Aprender a dibujar los contornos del país: Vínculos entre la enseñanza del dibujo escolar y los conocimientos geográficos en el Buenos Aires finisecular (1880-1900)
}

\author{
Learning to Draw the Contours of the Country. \\ Links between School Drawing and Geographic Knowledge in Elementary Education. Buenos \\ Aires (1880-1900).
}

Patricia Andrea Dosio

Doctoranda em Historia (Universidad Torcuato Di Tella)

Profesora Universitaria en la Universidad de Palermo y en la Universidad Nacional de Tres de Febrero patricia_dosio@yahoo.com.ar

\begin{abstract}
Resumen
En este artículo se indagará la contribución de la materia Dibujo a la transmisión de saberes sobre el espacio en la escuela elemental finisecular argentina a partir de la enseñanza del dibujo geográfico, tópico que, en los inicios del sistema de instrucción pública, fue parte de los contenidos de esta asignatura.
\end{abstract}

Palabras clave: Dibujo - enseñanza - geografía - escuela primaria - Argentina

\begin{abstract}
This article discusses the contribution of Drawing to the transmission of knowledge about space in argentine elementary education through the geographic drawing, topic that, at the beginning of the public school system, was part of the school subject Drawing.

Keywords: Drawing - education - Geographic - elementary school - Argentina
\end{abstract}

\section{INTRODUCCIÓN}

En este artículo se indagará la transmisión de saberes sobre el espacio en la escuela elemental argentina a partir de la enseñanza del dibujo geográfico, tema que, en los inicios del sistema de instrucción pública, fue parte de los contenidos de la asignatura Dibujo. Asociada a la gestación de la identidad nacional, una de las funciones que se vislumbró en la inclusión curricular del dibujo remitía al saber territorial. Dentro de los contenidos de la materia se contemplaba al dibujar como instrumento para el conocimiento del territorio, al facilitar el aprendizaje y comprensión de conceptos espaciales mediante el trazado de mapas, planos, el delineado de accidentes geográficos y otras aplicaciones. Si bien estos tópicos del temario curricular no se observaron en todos los programas de la asignatura durante el lapso acotado después de la sanción de la Ley de Educación Común (1884), no es un dato menor. Domingo F. Sarmiento ya había adherido a una enseñanza de tipo visual para el conocimiento de los aspectos territoriales e identificatorios del país, propiciando el empleo de imágenes en los muros del aula y en los libros relativas a aspectos típicos de la fauna y flora, de los hábitos y costumbres nacionales. La fuerza 
persuasiva de la cultura visual se sumaba a la necesidad de incentivar el conocimiento del espacio territorial. La construcción de una nación de ciudadanos, de individuos reunidos bajo las mismas tradiciones fue de la mano de la consolidación del espacio nacional, pues éste es el sostén físico de la ciudadanía.

Acotemos que, si bien se estimaba el empleo de imágenes en la enseñanza de la geografía, llegando a ser considerada la instrucción visual como el método más adecuado de enseñar los conocimientos geográficos (RYAN, 2004), este uso didáctico extrapoló los límites de esta materia escolar. Efectivamente, desde la asignatura Dibujo se comenzó a proponer la producción de imágenes como actividades de los alumnos, justamente, con el objeto de favorecer la aprehensión del espacio territorial. Esta producción requería la incorporación previa dentro de la misma materia de los saberes básicos de representación espacial. Al respecto, cuando se introdujo un tratado elemental de dibujo de mapas en las escuelas de la provincia de Buenos Aires, se sugería que el niño hiciera uso de figuras geométricas o diagramas de sencilla construcción para favorecer su recuerdo, pues el mejor medio de estudiar los mapas, se sostenía, era dibujándolos ${ }^{1}$.

Con este objetivo, en primer lugar se recorrerán las observaciones de Sarmiento con relación al empleo de recursos visuales para el entendimiento de la geografía, para luego explorar los programas de la asignatura Dibujo con el fin de identificar lo relativo al aprendizaje del espacio en tanto territorio. Asimismo, se revisarán las críticas que se formularon sobre esta articulación entre el lenguaje visual propio de la materia dibujo y el lenguaje también convencional de la cartografía.

Teniendo en consideración las características de nuestro objeto de estudio situado entre distintos campos disciplinares, la historia del arte, la historia de la educación y la geografía, esta pesquisa se enmarca dentro de una perspectiva interdisciplinar de los estudios visuales que han aportado renovados enfoques teóricos y metodológicos para la interpretación del período. Asimismo, nuestro artículo enlaza con las investigaciones recientes dentro del campo de la geografía que han focalizado en el carácter visual de la disciplina y su participación en las formas de mirar, pensar, representar y entender el mundo.

Por último, es importante señalar que la naturalización de la asignatura Dibujo a lo largo de su institucionalización dentro del sistema educativo público fue ocultando la intención por internalizar valores y comportamientos adecuados a las necesidades políticas en determinados momentos históricos. De allí que el área del dibujo, lejos de ser un conjunto de saberes de tipo técnico, de aplicación y, por lo tanto, acríticos, faltos de compromiso político o ideológico y ahistóricos, supuso la interiorización de conductas y hábitos que se fueron sistematizando, estereotipando y naturalizando a lo largo del proceso de institucionalización de los sistemas públicos de escolarización. 


\section{SARMIENTO Y EL CONOCIMIENTO DEL ESPACIO A TRAVÉS DE LO VISUAL}

Domingo Faustino Sarmiento (1811-1888) fue uno de los intelectuales partícipes del proyecto fundacional del Estado Nación argentino. Su pensamiento asistió de diversos modos a la definición del espacio geográfico nacional. Desde sus escritos tempranos, donde se exponían las características polarizaciones ciudad/campo, montaña/llanura y sus asociaciones con el espacio civilizado/espacio bárbaro, hasta sus declaraciones sobre la enseñanza del territorio nacional y los recursos visuales necesarios para estimular su aprendizaje en los niños.

Del mismo modo, su ideario propiciaba las bondades del enseñar dibujo en la escolaridad primaria. Las apreciaciones de Sarmiento por las cuestiones visuales y estéticas eran también de larga data. En sus años chilenos, había escrito numerosas críticas y notas sobre arte y educación, publicadas en los diarios El Progreso y El Nacional (FEVRE, 2001, p. 23). En algunas de ellas llegó a expresar que la adquisición del dibujo era menos un adorno o complemento educativo que "el fin a que debe conducir la instrucción popular" ("Del estudio del dibujo lineal” citado en GARCÍA MARTÍNEZ, 1985, p. 72). Asociaba la implementación de su enseñanza al desenvolvimiento industrial y cultural del país y lo erigía en indicador de la grandeza de las naciones y de su grado de civilización, congruente con el dogma decimonónico respecto a las artes en general: "En América la enseñanza del dibujo lineal, popularizada por nuestras escuelas primarias, está llamada a obrar una revolución completa en nuestras costumbres, y a abrir las puertas hasta hoy cerradas a la industria."

Y agregaba con respecto al pasado hispánico que el dibujo lineal tenía la capacidad de correctivo "del vicio orgánico de nuestra educación española" (GARCÍA MARTÍNEZ, 1985, p. 73). Es claro que desde su perspectiva el dibujo comportaba significaciones en lo cultural como en lo político. En esta dirección, la prédica sarmientina estaba impactada por sus contactos con la escuela norteamericana y específicamente con los escritos de Horace Mann, uno de los primeros defensores de la introducción del dibujo como asignatura obligatoria en Massachusetts. Defensa que se asociaba a la necesidad de cubrir las demandas de una joven nación industrial moderna. En la incipiente sociedad industrial del norte la necesidad de obreros calificados incidió en el desarrollo de un enfoque productivo en Dibujo. Su implantación aportaría a la moral y el comportamiento ordenado frente a la pobreza y criminalidad, resultado del crecimiento urbano y fabril (EFLAND, 2002, p. 120). Estos intereses compartidos por Sarmiento caracterizaron también la orientación inicial que se le dio a la asignatura en nuestro medio.

Durante su estadía en Londres, como parte del viaje de estudios encargado por el ministro chileno Manuel Montt, Sarmiento tomó contacto con el informe de Mann sobre educación que

\footnotetext{
${ }^{1}$ Cursivas en el original. "Bibliografía”, El Monitor de la Educación Común, 15 enero 1891, № 192, Año, XI, p.1014. 
determinó su partida hacia Nueva Inglaterra. Fue en su primer viaje, en 1847, cuando conoció a Mann y a su esposa, Mary Peabody Mann, quien colaboraría con Sarmiento para la selección y viaje a la Argentina de las maestras norteamericanas ${ }^{2}$. En su crónica de 1866 sobre la educación en los Estados Unidos, Sarmiento ponderó la función del arte y también de los oficios artesanos, consecuencias prácticas de la ciencia, para la formación social y laboral del pueblo.

A estas bondades del dibujo añadió el reconocimiento de la relevancia que poseía el aprendizaje de un tipo específico de dibujo, el dibujo lineal, de base racional, en la lectura de la geografía y su acción civilizadora para el progreso del país, reiterando convencido de que su estudio desplazaría todo resabio español e indígena, sinónimos de barbarie y atraso, según su óptica epocal:

Enseñemos a leer, a leer bajo todas sus faces, con toda la posible preparación para leer con fruto (la jeografía es elemento de lectura; la aritmética es leer; el dibujo lineal es objeto de lectura como la escritura misma), i cambiaremos los destinos del país, sustituyendo al pueblo que han dejado promaucaes, españoles i araucanos, inepto para el progreso, un pueblo capaz de seguir al mundo industrial moderno en la rápida marcha que lleva (SARMIENTO, 1866, p. 125).

Sarmiento asimismo subrayó el uso de la imagen como estrategia didáctica en primaria para el aprendizaje del espacio geográfico ${ }^{3}$. En su descripción sobre las escuelas norteamericanas, Sarmiento resaltó el empleo en las aulas de grandes mapas murales y el hecho de que en los libros “más papel hacen las figuras de animales peculiares de cada país y los trajes de los habitantes, que las palabras que los explican" (SARMIENTO, 1913, p. 235). En efecto, los mapas físico-políticos murales se combinaban con las cartas murales, representaciones de flora y fauna autóctonas y otras ilustraciones y pinturas que proliferaron en algunas escuelas como puede observarse en las fotografías de álbumes escolares o en los detalles de compras de materiales ${ }^{4}$.

Las apreciaciones de Sarmiento nos lleva además a interrogarnos por cómo era entendida la geografía escolar entonces. Esto es, por qué nucleaba principalmente lo relativo a visiones físicas y políticas así como a imágenes de lo característico de cada lugar. La geografía escolar comenzó siendo una asignatura auxiliar de la historia, para alcanzar autonomía en la década del ochenta. Sus programas de 1888, 1891, 1896 y 1901 evidenciaban el tratamiento de la geografía resaltando el aspecto físico, descripto en relación a las categorías de llanura, bosque y cordillera. Se ha señalado que estas categorías se conectaban con la literatura de viajes de principios de siglo y que conformaban las figuras paisajísticas sobre la geografía argentina (PRIETO, 1996). En la década del noventa del siglo diecinueve se expandieron las unidades descriptivas (orografía, hidrografía,

\footnotetext{
2 El Monitor de la Educación Común, abril-mayo 1961, № 937-938, Año LXXI, pp. 55-56.

3 El uso de las imágenes también fue debatido en: "La imagen en la escuela", El Monitor de la Educación Común, 30 abril 1903, № 362, Año XXIII, Tomo XIX, p. 73; "La imagen en la escuela", El Monitor de la Educación Común, 31 julio 1900, N 329, Año XX, Tomo XVII, pp. 490-491; Carlos Martinelli, "El dibujo y los maestros", El Monitor de la Educación Común, 30 abril 1915, № 508, Año XXXIII, Tomo LIII, pp. 625-631.

${ }_{4}$ Por ejemplo, "Útiles. Depósito del C.N. de Eucación”, El Monitor de Educación Común, 30 septiembre 1883, №39, DOI: $10.5752 / \mathrm{P} .2318-2962.2014 \mathrm{v} 24 \mathrm{n} 42 \mathrm{p} 90$ 
costas, clima); no obstante, lo político continuaba siendo central. En suma, la geografía escolar complementó los discursos epocales que apuntaban a la construcción y consolidación nacional.

Tanto el empleo de las representaciones planimétricas (esto es, mapas y planos) como perspectívicas (las imágenes de paisajes y vistas) se combinaban con la finalidad de incentivar los sentimientos de pertenencia a la nación argentina de una población de heterogéneos orígenes regionales y culturales ${ }^{5}$. Esta combinación de representaciones visuales con propósitos nacionalistas continuó en la organización del ámbito del aula y del contexto escolar así como en la enseñanza de temas más específicos. Por tanto, materias fundadas en lo visual, como lo es el Dibujo y la Geografía, se involucraron en esta prédica.

\section{EL CONTEXTO DEL SISTEMA DE INSTRUCCIÓN PÚBLICA}

En el proceso de institucionalización del Estado-nación, Oscar Oszlak identifica una modalidad ideológica de penetración estatal para constituir las bases consensuales sobre las cuales edificar un sistema de dominación. Esta modalidad apeló a mecanismos que operaron sobre valores, percepciones, actitudes, representaciones y comportamientos sociales asociados a sentimientos de pertenencia a una comunidad nacional. En ese marco, la educación fue el vehículo privilegiado de penetración ideológica, especialmente después de 1880 (OSZLAK, 1997, p. 151). A ello se sumó que entre 1880 y 1900 los afluentes migratorios se incrementaron masivamente. Pese a que la inmigración fue favorecía desde la dirigencia para fortalecer el crecimiento económico y social, paralelamente fue creciendo el pensamiento de la disgregación nacional por la llegada y asentamiento de migrantes que conservaban sus costumbres, idiomas y ataduras patrias. En relación a ello, una de las políticas desarrolladas por la élite dirigente durante la segunda mitad del siglo diecinueve fueron acciones de afirmación de la nacionalidad con la finalidad de integrar tanto al inmigrante como al indígena a los valores nacionales. Parte de esas acciones se canalizaron a través de los programas educativos, en especial de la escuela primaria.

En efecto, la escolarización, obligatoria a partir de 1884, reunió a una población infantil caracterizada por fuertes diferencias socioculturales. Al respecto Sandra Carli apunta que el alumnado de entonces englobaba a niños de grupos familiares socialmente y económicamente muy diversos, "cuya experiencia infantil estaba lejos de responder a un imaginario común”, puesto que "las historias infantiles estaban afectadas por la dispersión, las diferencias culturales y las desigualdades sociales fragantes" (CARLI, 2002, p. 36). Se trataba de hijos de inmigrantes que arribaron al país entre 1850 y 1870, a los que se sumaron descendientes de criollos que habían

Año II, pp. 661-662.

5 En especial a comienzos del siglo XIX, cuando la generación del conocimiento científico estaba unido a la DOI: $10.5752 /$ P.2318-2962.2014v24n42p90 
participado en las luchas intestinas y niños procedentes de familias oligárquicas. En consecuencia, una población infantil heterogénea cuyo emparejamiento cultural se convirtió en uno de los objetivos de las políticas educativas oficiales.

La insistencia en el carácter nacional de la instrucción pública fue una línea de acción política dependiente del proceso de constitución del Estado-nación. La necesidad de homogeneización cultural que requería este proceso ha sido señalada por los historiadores de la educación (ASCOLANI, 2009, p. 29). Al respecto, Juan Carlos Tedesco afirma que el grupo dirigente había logrado su hegemonía a través de instrumentos culturales con el fin de garantizar una homogeneidad cultural básica. En este sentido, Carlos Escudé califica como fuertemente nacionalista la postura del Consejo Nacional de Educación, cuyo presidente desde 1908, José María Ramos Mejía, se había empeñado en deseuropeizar a los inmigrantes concediéndoles una nacionalidad argentina creada artificialmente (ESCUDÉ, 1990, p. 33). Esta política atravesó las etapas que describe Roberto Marengo en su periodización de la formación del sistema educativo estatal. A una primera etapa de estructuración (1884-1899) le siguió otra de expansión (1899-1908) en la que se buscó abarcar a toda la población dentro del sistema de escuelas comunes. La última etapa, de consolidación (1908-1916), se caracterizó por la extensión del sistema administrativo y de control (MARENGO, 1991).

En este contexto, la enseñanza primaria se dividía en seis grados distribuidos en escuela infantil, elemental y superior. La planificación de los estudios de las escuelas comunes contemplaba Lectura, Escritura simultáneas, Idioma Nacional, Historia Argentina y nociones de Historia General, Geografía de la República y nociones de Geografía General, Instrucción Cívica, Aritmética, nociones de Geometría, de Ciencias Físicas y Naturales, nociones de Higiene, Moral y Urbanidad, nociones de Dibujo y de Música, Gimnasia, además de Labores de mano y Economía doméstica para las niñas y nociones de Agricultura y Ejercicios militares para los varones, de acuerdo a la planificación de $1888^{6}$. El modelo pedagógico imperante, de educación moderna, objetiva e intuitiva, se fundaba en el entendimiento racional y la percepción sensible de la realidad como principios del aprendizaje (FELDMAN, 2004, p. 80).

La concepción intuitiva fue resultado de la articulación del método pestalozziano con desprendimientos del positivismo, como el naturalismo biológico y el evolucionismo antimecanicista o a través del spencerianismo. Es que en Argentina, el positivismo tuvo una recepción particular que lo diferenció de los contextos europeo y estadounidense, definiendo distintas direcciones filosóficas.

A la luz de este pensamiento, el uso de las imágenes en la enseñanza era postulado como

producción de imágenes, compartiendo presupuestos epistemológicos (Sánchez, 2009; Wise, 2006).

6 "Plan de estudios, programas y horarios para las escuelas comunes", El Monitor de la Educación Común, 30 abril

DOI: 10.5752/P.2318-2962.2014v24n42p90 
central en el desarrollo de las facultades mentales de los niños, al ser consideradas como representaciones del origen de todo conocimiento verdadero. Por ello, la insistencia en el empleo de figuraciones fue una constante ${ }^{7}$. En el Primer Congreso Pedagógico de la Exposición Continental celebrado en Buenos Aires en 1882, del que fuera proyección la Ley de Educación Común, se afirmó que el uso de dibujos, láminas y pinturas de paisajes, entre otros artefactos visuales, serviría para conocer la naturaleza, despertando "mas emociones é ideas que la simple descripcion, ó la esplicacion impresa, manuscrita, ó de viva voz" ${ }^{\prime 8}$. La introducción en la escuela del conocimiento a través de lo visual representó una tendencia altamente difundida por didactas y pedagogos. A nivel nacional, por razones tecnológicas y económicas, las imágenes proliferaban en los muros de las aulas más que en las páginas de los libros como lo ponderaba Sarmiento ${ }^{9}$.

Los contenidos teóricos como los recursos visuales de Geografía en tanto disciplina escolar respondieron a la necesidad de promover una identidad nacional a través del sistema educativo en el contexto de conformación y consolidación del Estado-Nación argentino. En el caso de Dibujo, acompañando tal movimiento, observamos que en la mayoría de sus programas a lo largo del mismo período se incorporaron prácticas, ejercitaciones y conceptos orientados a la representación de espacios territoriales.

\section{LOS PROGRAMAS OFICIALES DE DIBUJO Y EL DIBUJO GEOGRÁFICO}

La asignatura escolar que más beneficiaba a los saberes de la materia Geografía era Dibujo. Es que el aprendizaje y comprensión del territorio y de nociones espaciales se veía favorecido por el recurso al dibujo de mapas, de accidentes geográficos y trazados afines. De acuerdo a Ivor Goodson, parafraseando a Hobsbawm, una disciplina escolar es un ejemplo de invención de tradición y el proceso de transformación que atraviesa no está exento de conflictos en tanto que constituye un campo de poder (HOBSBAWM; RANGER, 2002; GOODSON, 1995 у 2000). Justamente, la historia de estas materias se caracteriza efectivamente por transformaciones en sus contenidos, sus denominaciones, sus límites y relaciones con otras disciplinas. En este sentido, la zona de contacto entre las asignaturas Dibujo y Geografía con respecto a su funcionalidad para contribuir a la construcción de la identidad nacional estaba constituida por la práctica del dibujo

\footnotetext{
$1888, \mathrm{~N}^{\circ} 129$, Año IX, p. 388.

7 También Hollman (2006) estudia la aportación de las ilustraciones en manuales argentinos de geografía en la configuración de imaginarios geográficos. Señala cómo la autoridad asignada a lo visual estructuró el discurso escrito escolar.

8 Carlos M. de Pena (1882): Objetos para la enseñanza primaria. Imprenta de Biedma, Buenos Aires, p. 27. El atrevimiento informa lo estético que también importa el dibujo. En programas y discursos de los ochenta este rasgo prácticamente no se menciona como objetivo a inculcar. Situación que se irá revirtiendo entrando al nuevo siglo.

9 En su mayoría eran láminas importadas de alto costo, hasta que en 1910 la creación de una dependencia estatal facilitó su producción y distribución escolar. Fotografías de salones con imágenes en muros, por ej., en: Consejo Nacional de Educación, (1889): Vistas Escolares. Álbum de fotos enviado a la Exposición Universal de París. Samuel Boote, Buenos Aires.
}

DOI: 10.5752/P.2318-2962.2014v24n42p90 
geográfico.

Incluso, en un manual de dibujo lineal editado entre 1870 y 1890, uno de los primeros textos sobre este tópico de autor nacional que se ha hallado, se expresaba la importancia que revestía el conocimiento de las formas de representar el espacio geográfico, sobre todo por las carencias que presentaban los libros escolares sobre el tipo de dibujo requerido para su formalización, pues "el estudio del dibujo geográfico se elude generalmente en los diferentes textos por las serias dificultades que presenta“"10. Las dificultades a las que hace referencia tienen que ver con la adquisición de los presupuestos geométricos básicos sobre la representación del espacio y de cuerpos o figuras volumétricas, aparte de los rasgos propios de la representación cartográfica.

Dibujar los mapas favorecía la memoria y comprensión de temas geográficos, pero llevar a cabo esa práctica entre los alumnos suponía fundamentalmente el manejo de nociones de dibujo geométrico. Un método propuesto por entonces sugería partir de la consideración de un mapa como un dibujo cualquiera, de esta manera reduciríamos "los contornos del país que se reproduce á una figura geométrica de las menos complicadas y más fáciles de recordar"11.

Dentro de la planificación de la escuela primaria, los contenidos mínimos de Dibujo fueron estipulados por la Ley de Educación Común de 1884. La estructura de Dibujo ponderaba sobre todo el dibujo lineal y sus inclinaciones técnicas. De todos modos, durante el período siempre estuvo abierto el debate sobre qué tendencia debía profundizarse en su enseñanza, si orientada a los oficios o a lo estético.

Por otro lado, en los planes oficiales de la escuela común en los inicios de la década del ochenta, no se ejercitaba el dibujo geográfico, siquiera en la materia Geografía. Hasta 1884 la vertiente del dibujo orientada a favorecer la aprehensión del espacio geográfico, aunque era reconocida su utilidad y eficacia, no se implementaba aún en la enseñanza escolar: "uno de los medios más eficaces para hacer efectivos los conocimientos adquiridos por el mapa, es sin duda alguna el dibujo de mapas, aunque en nuestras escuelas, cosa lamentable, no se pone en práctica" ${ }^{\prime 2}$.

Por el contrario, en los programas de Dibujo de fines de los ochenta y los noventa, así se dispuso. En concreto, se apeló e implementó el dibujo en función de su aplicabilidad hacia el conocimiento del paisaje y del espacio nacionales. Si observamos las planificaciones de Dibujo a lo largo de las décadas del ochenta y del noventa se revela esta derivación. En el plan de estudios correspondiente al año 1888 aprobado por el Consejo Nacional de Educación para las escuelas capitalinas se incluía la materia Dibujo en los seis años de escolaridad. En una noticia histórica sobre este plan se informa que se había puesto en práctica luego de su aprobación y debate

\footnotetext{
${ }^{10}$ Francisco Canale (1879?): Curso metódico de dibujo lineal. Estrada, Buenos Aires, p. 4.

11 El Monitor de la Educación Común, 31 julio 1891, N 199, Año XI, p. 1192.

12 Cursivas en el original. Un maestro, "Dibujo de mapas en las escuelas", L Revista Pedagógica, 1884, N 43, Año II, p. 451.
}

DOI: $10.5752 / P .2318-2962.2014 v 24 n 42 p 90$ 
acaecidos en $1887^{13}$. Es interesante señalar que el proceso aprobatorio se efectuó teniendo en consideración las opiniones de los subinspectores. Esta planificación además sustituyó a aquélla heredada de las autoridades escolares de la provincia de Buenos Aires y que tenían en vigencia desde 1876. En este plan, los contenidos de Dibujo para quinto grado abarcaban el "dibujo de mapas", "la construcción del mapa-mundi, del mapa de América y del mapa de la República Argentina", entre otros temas ${ }^{14}$. La materia Geografía, por su parte, incluía para ese mismo curso como sección práctica a la cartografía en el pizarrón y en los cuadernos, pero sin más especificaciones.

La articulación entre saberes geográficos y visuales así como su imbricación con cuestiones políticas y sociales adquirieron un espesor particular en las planificaciones de la escuela primaria. No es casual la irrupción de estos tópicos relativos al espacio territorial al momento en que empezaran a emerger preocupaciones por la nacionalidad y el desarrollo desde la dirigencia de tácticas para despertar el entusiasmo patriótico en la población, en especial la infantil ${ }^{15}$. La organización de los contenidos de Dibujo en los tres niveles o escuelas de la educación común también operó en el plan de 1892, donde se contempló para la escuela superior nuevamente el dibujo de mapas, junto con el dibujo de perspectiva, elementos de dibujo arquitectónico y de adorno $^{16}$.

A fines del año 1895 se presentó un programa donde se reestructuró la organización de las materias. Dibujo se inscribió dentro del área Estética junto con Música Vocal. El programa instructivo del área atendía nociones de forma, colorido, sonido y pensamiento ${ }^{17}$. Orientaciones muy generales, pero por ubicarse en un área estética hacen pensar en que se tendía a lo específico del lenguaje visual. En ese mismo año se publicaron en El Monitor de la Educación Común, órgano de comunicación oficial, unas aclaraciones para el programa de Geografía. Allí se ponderaba el empleo de las representaciones gráficas como imprescindibles para la enseñanza de las nociones geográficas, aunque "los mapas ofrecen, sin embargo, el mismo peligro que las formas" ya que a los niños les dificulta la comprensión de su naturaleza representacional ${ }^{18}$; por lo tanto, se aconsejaba no hacer un uso excesivo de tales representaciones en la enseñanza primaria.

Posteriormente, el programa oficial de Dibujo del año 1897, que abarcaba también de primero a sexto grados, contenía como parte de las aplicaciones de la materia temas lindantes con lo geográfico: para el primer grado el "dibujo de accidentes geográficos”, para el segundo "el contorno

\footnotetext{
${ }^{13}$ Esta noticia histórica fue publicada en "Conferencias pedagógicas. Sección Doctrinal”, El Monitor de la Educación Común, 31 octubre 1895, N²67, Año XV, p. 298.

14 "Redacción”, El Monitor de la Educación Común, Año XI, № 129, 30 abril 1888, p. 385-432 . Contenidos de quinto grado citados en p. 407.

15 Sobre el despertar entusiasmos patrios ver Bertoni (2001) (1996).

16 El Monitor de la Educación Común, 15 diciembre 1892, № 219, Año XI, p. 564.

17 El Monitor de la Educación Común, 30 noviembre 1895, № 268, Año XV, pp. 354-355.
}

DOI: 10.5752/P.2318-2962.2014v24n42p90 
de la República Argentina", para cuarto "itinerarios de viajes", y para quinto grado "vistas y monumentos de nuestro país, paisajes tomados de nuestro país" y "tintas y signos convencionales de topografía y geografía"19.

Dos años después se puso en discusión el propósito de reformar los programas de primaria, pero en lo atinente al Dibujo no se consideró necesaria su modificación, a excepción del dibujo geométrico que fue incluido en la materia Geometría ${ }^{20}$, continuando las aplicaciones antes mencionadas. En el proyecto de mayo de 1901 sobre la reducción de los programas vigentes en las escuelas públicas porteñas, la asignatura Dibujo conservó sus contenidos básicos dentro del grupo de materias obligatorias (según el artículo sexto de la ley) que respondían al "trabajo humano en su aspecto artístico". En la propuesta se observa que todas las materias obligatorias por ley, "han sido reducidas á cuatro grupos que responden a otros tantos puntos de vista comprensivos de las tareas instructivas y educativas á que puede ser sometido el niño, y que abarcan los diversos ramos del conocimiento".

De acuerdo a esta organización, Geografía junto con Historia e Instrucción Moral y Cívica se reunieron en el grupo tercero, mientras que la materias Dibujo, Lectura, Escritura, Idioma Nacional, Música, Labores de Mano y nociones de Economía Doméstica en el grupo segundo ${ }^{21}$. Era pues este último un conjunto de materias compuesto por saberes prácticos y la lengua nacional. En definitiva, el dibujo era visto como un lenguaje específico, un medio de expresión y comunicación que coadyuvaba al desarrollo de habilidades indispensables en una sociedad moderna en crecimiento. Sin embargo, en los contenidos para el quinto grado, retornaban las tendencias hacia lo geográfico: "Paisaje y adorno. Dibujo de mapas y monumentos. Lavado de planos. Signos y tintas convencionales ${ }^{، 22}$.

\section{PERMANENCIAS Y CRÍTICAS}

Esta funcionalidad del dibujo para el aprendizaje del espacio geográfico reapareció en los discursos de la siguiente centuria. Con motivo de una exposición escolar de dibujos, se invocaron las consecuencias inmediatas que su aprendizaje proporcionaría en otros saberes, puesto que "nuestras clases de dibujo inician y educan" por lo tanto las aplicaciones de estos conocimientos tienen incidencia "inmediatamente en las otras asignaturas: geografía, historia natural, física, etc.,

${ }^{18}$ El Monitor de la Educación Común, 15 noviembre 1897, № 294, Año XVII, p.626.

19 El Monitor de la Educación Común, 31 enero 1897, ํㅜ 283, Año XVII, pp.111-112.

${ }^{20}$ El Monitor de la Educación Común, 31 mayo 1899, № 314, Año XIX, Tomo XVI, p. 738.

21 La reducción de programas fue encargada a Andrés Ferreyra por el Consejo Nacional de Educación, presidido por José M. Gutiérrez. Las citas anteriores corresponden a: "Proyecto de reducción de los programas vigentes para las escuelas primarias de la Capital Federal”, El Monitor de la Educación Común, 31 marzo 1901, N 337, Año XXI, Tomo XVII, p. 969; detalle del segundo grupo de materias, pp. 970-976. El dibujo figuraba como Nociones de Dibujo.

22 El Monitor de la Educación Común, 31 marzo 1901, № 337, Año XXI, Tomo XVII, p. 974.

DOI: $10.5752 /$ P.2318-2962.2014v24n42p90 
etc."23. Las interrelaciones entre Dibujo, Geometría, Geografía e Historia conformaban un rasgo asentado y bastante corriente en el período ${ }^{24}$.

Podría afirmarse que se hizo converger la materia Dibujo hacia la tesis de que el conocimiento del territorio favorecía, entre otros saberes, el robustecimiento del sentir patrio. Con los años, la inclusión en la materia de contenidos y ejercicios asociados a los saberes geográficos y topográficos debe haberse generalizado, aun más de lo que los programas permiten entrever. Esto puede afirmarse en base a los cuestionamientos de que fuera objeto por parte del artista y crítico de arte argentino Fernando Fusoni. Específicamente, su impugnación se fundaba en que:

El dibujo de accidentes geográficos es una forma convencional de representar el aspecto que presentan pequeñas zonas de tierra, indicando con precisión todos sus pormenores. Es un dibujo abstracto que, en realidad, casi no puede llamarse dibujo, porque la representación de los datos topográficos se hace mediante signos convencionales que ninguna relación de semejanza tienen con los objetos representados. Constituye una simple habilidad manual sin valor educativo como dibujo.

[...] Se exige [en la escuela] la ejecución de mapas, desarrollo del cubo, dibujos para recuadros de habitaciones, etc. Los mapas, indudablemente, constituyen ejercicios prácticos de geografía ${ }^{25}$.

Es posible conjeturar que la "simple habilidad manual" implicada en el dibujo según el autor, refiera a la conversión de un fenómeno espacial en una representación en apariencia acrítica y atemporal de algo dado, aunque es sabido que el lenguaje convencional cartográfico lejos se encuentra de estos atributos. Además, su diferenciación entre el dibujo y la representación cartográfica encierra una intención por rescatar al dibujo figurativo artístico. Esto es, una vertiente más cercana al arte visual que a lo aplicado.

Más allá de los cuestionamientos formulados por Fusoni, lo cierto es que los vínculos entre las asignaturas Dibujo y Geografía estaban presentes en los planes oficiales, en tanto el aprendizaje del dibujar fue un recurso satisfactorio para facilitar aprehender el espacio territorial. Y esta aprehensión, a su vez, conduciría a un acercamiento a los valores nacionales, al sentido de pertenencia e identificación nacional. Ateniéndose a estos aspectos, es posible afirmar que la dirección patriótica de comienzos del siglo veinte, en la que se encauzó la educación en general y la enseñanza del arte por medio del dibujo en particular, tenía sus antecedentes en la propia configuración de la asignatura a través de su empleo subsidiario para el saber territorial, para la apropiación del espacio nacional y su ubicación en el mundo, tópicos concurrentes en los programas

\footnotetext{
${ }^{23}$ El Monitor de la Educación Común, 31 julio 1905, № 403, Año XXVI, Tomo XXIII, p. 11.

24 Inclusive a nivel internacional, como lo atestigua una memoria (1917) sobre concursos para cátedra de Dibujo en instituto español, donde todavía se sostenía este argumento: el Dibujo "con la geometría se completa, para la geografía es indispensable y juntamente con esta ciencia contribuye al conocimiento de la Historia ... La fisiología también se ayuda del dibujo y hasta la física”. Bermúdez Abellán (2007, p. 327).

${ }^{25}$ El Monitor de la Educación Común, 31 enero 1899, № 310, Año XIX, Tomo XVI, p. 389.
}

DOI: $10.5752 / \mathrm{P} .2318-2962.2014 \mathrm{v} 24 \mathrm{n} 42 \mathrm{p} 90$ 
de fines de los ochenta y noventa.

\section{IDEAS FINALES}

La elección del dibujo para enseñar en el nivel primario frente a las otras disciplinas dentro del área artística, como la historia del arte o los estilos, se hallaba en sintonía con los desarrollos internacionales. No obstante, en el caso local se adicionó el incentivo de la nacionalidad que, entre otras condiciones, requería un acercamiento visual al espacio geográfico. De hecho, esta cuestión se vislumbra al parangonar la situación norteamericana y la argentina. En el primer caso, la contemplación del orden social y del crecimiento económico signaban los debates que justificaban la inclusión del dibujo en la escuela primaria norteamericana. Su introducción por ley en Massachusetts obedeció al pasaje de una economía agrícola a una economía industrial.

En cambio, en el caso argentino el dibujo se asoció a otros valores, definiendo otros rumbos. Se trataba tanto de configurar una nación de ciudadanos unidos por referentes comunes donde lo territorial desempeñó un rol relevante. Conocer el territorio fue uno de los requerimientos para identificarse con el colectivo Nación. Por ello, la presencia de saberes relacionados con el espacio propio en las escuelas, que eran verdaderos conglomerados de nacionalidades, colaboraría en tal identificación y en la homogenización cultural. Los saberes sobre el espacio natural y cultural se impartían mediante las asignaturas Geografía e Historia, a través de la frecuentación de imágenes de costumbres y paisajes en láminas, libros, muros de los salones y la práctica concreta de dibujar los contornos del país.

Se han detallado los programas aprobados por el Consejo Nacional para las escuelas comunes porteñas donde se incorporaron estas ejercitaciones orientadas al dibujo de mapas, a la representación gráfica del mundo, del continente americano y de la Argentina ${ }^{26}$. Sin embargo, estas actividades y prácticas no consistían apenas en aprender a dibujar mapas. Respondían además a la acentuación en lo visual propia de la cultura de esos tiempos y al pensamiento que veía al dibujo y su potencial como propicios para incentivar el sentimiento de lo nacional.

A medida que la Geografía fue conformando su estatuto como disciplina escolar, estos saberes vinculados al territorio fueron restringiéndose de Dibujo e insertándose en la otra asignatura. No obstante, con la orientación patriótica liderada por José María Ramos Mejía cuando, hacia 1904, se hizo cargo de la presidencia del Consejo Nacional de Educación e incentivó la ponderación de lo visual, los aspectos típicos del territorio nacional continuaron como imágenes identitarias, tópicos a partir de los cuales también se aprendía Dibujo. Así, podría decirse con respecto a este punto, que el desplazamiento más notorio en esta materia dentro de la etapa acotada 
se vinculó con la orientación nacionalizante. Esto es, el desplazamiento del dibujo de contorno y planimétrico que se aplicó al dibujo de mapas, hacia una enseñanza del dibujo de la imagen perspectívica de íconos patrios y paisajes característicos.

Dibujo participó en la formación de actitudes y predisposiciones que debía tener un ciudadano. A estas se sumaron cuestiones culturales, como lo fueron el conocimiento de la geografía, la historia y el idioma nacionales. Cuestiones que mutatis mutandis incorporó la materia Dibujo de modo transversal, ora como acercamiento a la geografía nacional con el dibujo de mapas, ora con la representación de símbolos e iconografías patrias, ora con su conceptualización posterior como medio de expresión.

\section{REFERENCIAS}

Argentina. Ministerio de Justicia e Instrucción Pública. Epistolario entre Sarmiento y Posse. 1845-1888. v. I, n. 1., Buenos Aires: Archivo Museo Histórico Sarmiento, 1946.

Augustowsky, Graciela. Las paredes del aula. Un estudio del espacio dispuesto por docentes y alumnos. Arte, Individuo y Sociedad, n. 15, 2003, p. 39-59.

Bermúdez Abellán, Juan. Génesis y evolución del Dibujo como disciplina básica en la Segunda Enseñanza. Tesis Doctoral, Universidad de Murcia, 2005. Disponible en: http://digitum.um.es/xmlui/bitstream/10201/4158/1/BermudezAbellan.pdf. Acceso el: 08 nov. 2012.

Bertoni, Lilia. A. Patriotas, cosmopolitas y nacionalistas. Buenos Aires: Fondo de Cultura Económica, 2001.

BERTONI, Lilia. A. Nacionalidad o cosmopolitismo. La cuestión de las escuelas de las colectividades extranjeras a fines del siglo XIX, Anuario del IHS, n. 11, p. 179-199, 1996.

BOTTARINI, Roberto. Leer, escribir, votar: la conflictiva definición del curriculum ciudadano, en Héctor Cucuzza, dir. y Pablo Pineau, codir. Para una historia de la enseñanza de la lectura y la escritura en la Argentina: del catecismo colonial a La Razón de Mi Vida. Buenos Aires: Miño y Dávila Editores, 2002, p. 77-105.

CARLI, Sandra. Niños, pedagogía y política. Transformaciones de los discursos acerca de la infancia en la historia de la educación argentina entre 1880 y 1955 . Universidad de Buenos Aires, Buenos Aires: Miño y Dávila, 2002.

Cosgrove, Denis. Observando la naturaleza: el paisaje y el sentido europeo de la vista, Boletín de la A.G.E. Universidad de California, n. 34, p. 63-89, 2002.

EFLAND, Arthur. D. Una historia de la educación del arte. Barcelona: Editorial Paidós, Colección Arte y Educación, 2002.

${ }^{26}$ El Monitor de la Educación Común, 30 abril 1888, N 129, Año IX, p. 407.

DOI: $10.5752 / \mathrm{P} .2318-2962.2014 \mathrm{v} 24 \mathrm{n} 42 \mathrm{p} 90$ 
ERrÁzuriz, L. H. Historia de un área marginal. Santiago de Chile: Ediciones de la Pontificia Universidad Católica de Chile, 1994.

FEldman, Daniel. Imágenes en la historia de la enseñanza: la lámina escolar, Educación y Sociedad, v. 25, n. 86, p. 75-101, 2004.

FeVre, Fermín. Orígenes periodísticos de la crítica de arte. Academia Nacional de Periodismo, Buenos Aires: Dunken, 2001.

García Martínez, Juan. A. Arte y enseñanza artística en la Argentina. Buenos Aires: Fundación Banco de Boston, 1985.

GoODSON, Ivor. Historia del curriculum. La construcción social de las disciplinas escolares. Barcelona: Pomares-Corregidor, 1995.

Goodson, Ivor. El cambio en el curriculum. Barcelona: Octaedro, 2000.

Hobsbawn, Eric, RAnger, T. La invención de la tradición. Barcelona: Crítica, 2002.

HOLlmAN, Verónica. La geografía crítica y la subcultura escolar: una interpretación de la mirada del profesor. Tesis de Doctorado (Educación) Buenos Aires: FLACSO, 2006. Disponible en:

http://www.flacso.org.ar/uploaded_files/Publicaciones/Tesis_Veronica_Hollman.pdf. Acceso el: 8 nov. 2012.

HOLLMAN, Verónica. Imágenes e imaginarios geográficos del mundo en la geografía escolar en Argentina. Anales de Geografía, v. 30, n. 1, p. 55-78, 2010.

MARENGO, Roberto. Estructuración y consolidación del poder normalizador: el Consejo Nacional de Educación, en Adriana Puiggrós dir. Sociedad civil y Estado en los orígenes del sistema educativo argentino. Buenos Aires: Galerna, 2001.

Martínez, Alberto. B. Censo General de Educación. v. III, s.l., s.e., 1909.

Morán, M. L. Espacios y ciudadanos: los lugares de la narración clásica de la ciudadanía. Reis, Universidad Complutense de Madrid, n. 119, p. 11-34, 2007.

OSZLAK, Oscar. La formación del estado argentino. Buenos Aires: Planeta, 1997.

PRIETO, Adolfo. Los viajeros ingleses y la emergencia de la literatura argentina, 1820-1850. Buenos Aires: Sudamericana, 1996.

Puiggrós, Adriana. La educación popular en América Latina. México: Nueva Imagen, 1987.

QuinTERo PAlacios, Silvina. Estrategias educativas en la representación del territorio argentino (1862-1870). Serie Territorio, n. 7, Facultad de Filosofía y Letras, Universidad de Buenos Aires, 1995.

Romero, Luis. A. La Argentina en la escuela. La idea de nación en los textos escolares. Buenos Aires: Siglo XXI Editores, 2004. 
Ryan, James. On visual instruction, en V. Schwartz y J. Przyblyski, eds., The nineteenth century visual culture reader. London: Routledge, p. 145-151, 2004.

SÁnchez, A. Ciencia moderna, cultura visual, epistemología artesanal. Asclepio. Revista de Historia de la Medicina y de la Ciencia, vol. LXI, n. 1, p. 259-274, 2009.

SARMIENTO, Domingo F. Las escuelas base de la prosperidad i de la republica en los Estados Unidos. Informe al ministro de instrucción Pública de la República Argentina, Nueva York: s./e., 1866. Disponible en:

http://www.proyectosarmiento.com.ar/trabajos.pdf/LAS\%20ESCUELAS.pdf Acceso el: 8 nov. 2012.

SARMIENTO, Domingo F. Obras completas. Buenos Aires: La Facultad, 1913.

Sotos SERrano, C. La botánica y el dibujo en el siglo XVIII, Los pintores de la expedición de Alejandro Malaspina. Real Academia de la Historia, Madrid, vol. I, 1982.

TEDESCO, Juan. C. Educación y sociedad en la Argentina, 1880 -1900. Buenos Aires: Siglo XXI, 2009.

WISE, Nicholas. Making visible. Isis, n. 97, p. 75-82, 2006. 